\title{
Comparison of Intermediate Vs Subcutaneous Superficial Cervical Plexus Block for Anterior Cervical Discectomy and Fusion: A Prospective Randomized Controlled Study.
}

\author{
Sarasa K Sahoo', Panigrahi Souvagya ${ }^{2}$, Pradhan S Chandra ${ }^{3}$ \\ ${ }^{1}$ Assistant Professor, Department of Anaesthesiology, Andaman \& Nicobar Islands Institute of Medical Sciences \& GB Pant Hospital, Port Blair, India, \\ ${ }^{2}$ Associate Professor, Department of Neurosurgery, IMS and SUM Hospital, Bhubaneswar, India, ${ }^{3}$ Consultant, Department of Anaesthesiology, CARE \\ Hospital, Bhubaneswar, India.
}

\section{Abstract}

Background: Superficial cervical plexus has been used successfully for postoperative analgesia following anterior cervical discectomy and fusion (ACDF) surgery. It is not known if superficial and intermediate cervical blocks are equally effective, although anatomical evidence suggests that the latter might provide superior quality of analgesia. The aim of our study was to compare the effect of intermediate cervical plexus block (ICPB) vs superficial cervical plexus block (SCPB) on postoperative quality of recovery and analgesia in patients undergoing ACDF surgery. Subjects and Methods: Forty-nine patients were randomised to receive either bilateral ICPB or bilateral SCPB in patients undergoing elective single- or two-level ACDF surgery. The primary outcome measure was the quality of recovery at $24 \mathrm{hr}$, measured using the 40-item quality of recovery questionnaire (QoR-40). In addition, comparisons between groups were also made for intra- and postoperative opioid consumption. Groups were compared using Student's t test, Mann-Whitney U test or Chi-square test for different type of data. A pvalue of $<0.05$ was considered statistically significant. Results: The mean (SD) aggregated global QoR-40 scores at $24 \mathrm{hr}$ were significantly greater in the ICPB group, indicating good quality of recovery compared with the SCPB (186 \pm 9 vs $173 \pm 12$, respectively; P = 0.001). Intraand postoperative opioid consumption was significantly higher in SCPB group. No major block related complications were noticed during the study. Conclusion: We showed that compared to SCPB, ICPB provides better analgesia in patients undergoing single- or two-level ACDF, thereby improving the early quality of recovery. We strongly believe the existence of investing layer of cervical fascia of neck.

Keywords: ACDF, cervical plexus block, investing layer, QoR-40.

Corresponding Author: Dr Sarasa K Sahoo, Assistant Professor, Department of Anaesthesiology, Andaman \& Nicobar Islands Institute of Medical Sciences \& GB Pant Hospital, Port Blair, India.

Received: September 2019

Accepted: September 2019

\section{Introduction}

Anterior cervical discectomy and fusion (ACDF) is one of the most commonly performed procedure for degenerative spinal disease. ${ }^{[1]}$ Pain and discomfort after ACDF is difficult to quantify as these patients often experience painful swallowing, dysphagia, and position-related occipitonuchal pain in addition to incisional pain. ${ }^{[2-4]}$ Postoperative pain has been reported as moderate in this group of patients, requiring a combination of opioid and non-steroidal anti-inflammatory drugs as analgesics. Nevertheless, opioid-related side effects, including nausea, vomiting, and respiratory depression, are undesirable in these patients who are at risk for airway complications due to airway edema secondary to surgical retraction or wound hematoma. ${ }^{[5-7]}$

Peripheral nerve block, as a part of a multimodal analgesic technique, provide site-specific pain relief with few side effects and have been shown to be effective for improving the quality of recovery. ${ }^{[8]}$ Superficial cervical plexus block
(SCPB) and intermediate cervical plexus block (ICPB) are safe and simple techniques that has been shown to provide good pain relief for both incisional pain and the occipitonuchal pain after thyroid and carotid surgeries. ${ }^{[4,9,10]}$ In case of SCPB, the local anaesthetic drug is deposited subcutaneously, above the investing fascia of the neck, whereas in ICPB, the drug is injected below the investing fascia [Figure 1]. ${ }^{[1]}$ These two techniques of cervical plexus block has been compared in the past but the results are conflicting in nature. ${ }^{[10,12-14]}$

Postoperative pain is an important component of quality of recovery after surgery; however, assessment of only pain outcomes after surgery does not completely describe the full dimensions of the quality of recovery. Among the multiple tools available to access the quality of recovery after anaesthesia and surgery, the 40-item quality of recovery questionnaire (QoR-40) is one of the validated multidimensional tools that has been shown to be suitable to assess the effect of interventions in anaesthesia that are 
armea at improving the quality of recovery and improving patient satisfaction. ${ }^{[15]}$ The questionnaire measures various dimensions of recovery, including pain, nausea and vomiting, physical independence, physical comfort, emotional state, and psychological support. ${ }^{[16]}$

\begin{abstract}
Aim:
The main objective of this study was to compare SCPB and $\mathrm{ICPB}$, in terms of, postoperative quality of recovery and analgesia in patients undergoing ACDF. We hypothesised that as the drug is placed below the investing layer of neck in case of ICBP, compared to SCPB; it will spread into deeper structure and would reduce postoperative pain and discomfort, thus improving the quality of recovery at $24 \mathrm{hr}$ as measured by the QoR-40 questionnaire.
\end{abstract}

\section{Subjects and Methods}

This prospective, randomized, double blinded, comparative study was carried out after approval from the Institutional Ethics Committee of our hospital and written informed consent was obtained from eligible 49 patients. Patients of American Society of Anaesthesiologists (ASA) Grade I and II, aged 18-60 years of either sex, undergoing elective, single- or two-level ACDF were considered for entry into the study. Exclusion criteria included patients with history of allergy to local anaesthetics, pregnancy, known diaphragmatic motion abnormalities, and patients with known psychiatric or neurological condition that would affect the completion of the QoR-40 questionnaire.

Patients were randomised by means of computer-generated random numbers into two groups: superficial cervical plexus block (SCPB) group and intermediate cervical plexus block (ICPB) group (Figure 2). Group assignments were sealed in sequentially numbered opaque envelopes that were opened by research personnel not involved in patient care or data collection. The assessors who were evaluating the postoperative patient outcomes were blinded to group allocation, but both the anaesthesiologist and the surgeon were not blinded.

Routine preparation of the patients was carried out as per our institutional standards for all patients undergoing ACDF surgery. Patients received standardized monitoring and an anaesthetic regimen consisting of intravenous fentanyl 2-3 $\mu \mathrm{g} / \mathrm{kg}$ and thiopentone sodium $4-5 \mathrm{mg} / \mathrm{kg}$, with vecuronium $0.1 \mathrm{mg} / \mathrm{kg}$ to facilitate endotracheal intubation. Anaesthesia was maintained with oxygen, air, and sevoflurane (approximately $1 \mathrm{MAC}$ ). A high frequency, linear transducer in transverse axis and in plane approach, along with 22 gauge, short bevel, and $50 \mathrm{~mm}$ Stimuplex ${ }^{\circledR}$ needle was used for performing the blocks, as described below.

SCPB: The head of the patient was turned to the opposite side and skin was cleaned with chlorhexidine. The transducer was placed over the lateral border of sternocleidomastoid muscle (SCM) and it was positioned such a way that the tapering end of the SCM remained on centre of the screen. The needle was introduced from the posterior aspect through the skin and platysma and $10 \mathrm{ml}$ of $0.25 \%$ of bupivacaine deposited behind this landmark. The goal was to inject the local anaesthetic drug, subcutaneously above the investing fascia of the neck. The procedure was repeated on the opposite side.

ICPB: The patient was positioned and scanned in a similar way, the investing fascia was identified and $10 \mathrm{ml}$ of $0.25 \%$ bupivacaine deposited under the fascia. We tried to feel for a click or 'pop' when the needle pierced this fascia. The procedure was repeated on the opposite side.

Intraoperatively, all patient received ondansetron $0.15 \mathrm{mg} / \mathrm{kg}$ (maximum dose of $8 \mathrm{mg}$ ) IV towards end of surgery for postoperative nausea and vomiting (PONV) prophylaxis. A $20 \%$ increase in heart rate and/or blood pressure from the preoperative baseline was treated with fentanyl boluses of 25 $\mu \mathrm{g}$ at 2.5- minute intervals until vital signs returned to baseline. ${ }^{[17]}$ At the end of the surgery, sevoflurane was turned off and the neuromuscular blockade was reversed with neostigmine $(50 \mu \mathrm{g} / \mathrm{kg})$ and glycopyrrolate $(10 \mu \mathrm{g} / \mathrm{kg})$.

Patients were monitored for the first $24 \mathrm{~h}$ postoperatively in a high dependency unit with standard monitoring facility including continuous oxygen saturation monitoring. Postoperative pain was assessed using an 11-point numeric rating scale (NRS; $0=$ no pain, $10=$ worst possible pain). All patients received IV paracetamol 1 gm every $6 \mathrm{~h}$ for $24 \mathrm{~h}$ as postoperative analgesia. Breakthrough pain was treated with bolus dose of Morphine $2 \mathrm{mg}$ IV and repeated every five minutes to maintain NRS of $<4$. Degree of sedation was measured by Ramsay sedation score; if awake, $1 \square$ anxious, agitated, restless, $2 \square$ cooperative, oriented, tranquil, and 3 $\square$ responsive to commands only; if asleep $\square 4 \square$ brisk response to light glabellar tap or loud auditory stimulus, $5 \square$ sluggish response to light glabellar tap or loud auditory stimulus, and $6 \square$ no response to light glabellar tap or loud auditory stimulus. PONV and was managed with additional dose of IV ondansetron $0.15 \mathrm{mg} / \mathrm{kg}$ and /or dexamethasone 8 mg.

Patients were subjected to the QoR-40 questionnaire at $24 \mathrm{~h}$ after surgery by an independent investigator who was unaware of the group allocation. The questionnaire consists of 40 questions that examine five domains of patient recovery using a five-point Likert scale as follows: none of the time, some of the time, usually, most of the time, and all the time. The five domains assessed included emotional state, physical comfort, psychological support, pain and physical independence. Global QoR-40 scores range from 40-200 representing very poor to outstanding quality of recovery. ${ }^{[16]} \mathrm{We}$ also recorded any block-related serious complications, defined as any potential threat to life arising directly from block placement, e.g. intravascular or intrathecal injection of local anaesthetic, local anaesthetic toxicity, local trauma, or haematoma caused by the injecting needle of a severity that led to the cancellation of surgery, airway obstruction, or respiratory distress after placement of block but before surgery (e.g. owing to diaphragmatic or vocal cord paralysis).

The other data recorded included patient demographics, intraoperative fentanyl consumption and surgical data, postoperative pain score, sedation score, incidence of PONV, sore throat, dysphagia and the total analgesic consumption in the first $24 \mathrm{hr}$.

\section{Statistical analysis}

The mean (SD) QoR-40 score at $24 \mathrm{~h}$ after major spine 
surgery has been reported to be 160 (17). ${ }^{[18]}$ Previous studies have shown that a ten-point difference in QoR-40 score corresponds to $15 \%$ relative improvement in quality of recovery after surgery. ${ }^{[16]}$ In order to demonstrate a difference of ten points in the QoR-40 score, we calculated that 23 patients per group would be required to detect a significant difference between groups with an alpha of 5\% and power of $80 \%$ and assuming a baseline mean (SD) QoR40 of 160 (17). ${ }^{[18]}$ Therefore we included 25 patients in each group.

The primary outcome measure was the global QoR-40 aggregate score at $24 \mathrm{hr}$ after surgery. The secondary outcome measures were total opioid consumption during the intra- and post-operative period, side effects and complications.

Groups were compared using Student's t test for continuous data, Mann-Whitney U test for continuous non-parametric data and Pearson's Chi-square test for categorical data. Data were presented as mean (SD) for continuous data and as number for categorical data. A p-value of $<0.05$ was considered statistically significant. SPSS $®$ version 18 (Chicago, IL, USA) was used for all analyses.

\section{Results}

Forty-nine patients were recruited and randomised to receive either ICPB $(n=25)$ or SCPB $(n=24)$. There were no differences between the groups with regard to demographic and surgical data [Table 1]. Total fentanyl used during the intraoperative period was significantly more in SCPB group (Table 1). Mean (SD) aggregated global QoR-40 score at 24 $\mathrm{h}$ were significantly more in ICPB group, indicating better quality of recovery compared to SCPB group (186 \pm 9 vs 173 \pm 12 , respectively; $\mathrm{P}=0.001$ ) and the patients in the ICPB group had better mean scores in all five domains [Table 2]. The postoperative pain scores of were significantly lower in ICPB Group at all points of time over first postoperative $24 \mathrm{~h}$ [Table 3]. Cumulative morphine consumption during the postoperative period was significantly more in SCPB group at $24 \mathrm{~h}$ [Table 4]. The incidence of nausea, vomiting and dysphagia were significantly less in patients who received ICPB at $24 \mathrm{~h}$ after surgery, whereas the mean sedation score was comparable between the two groups at all points of times over the $24 \mathrm{~h}$ postoperative period and none of the patients had score $<2$ or $>4$ at any occasion (Table 4 ). There were no adverse events or serious complications reported in either group.

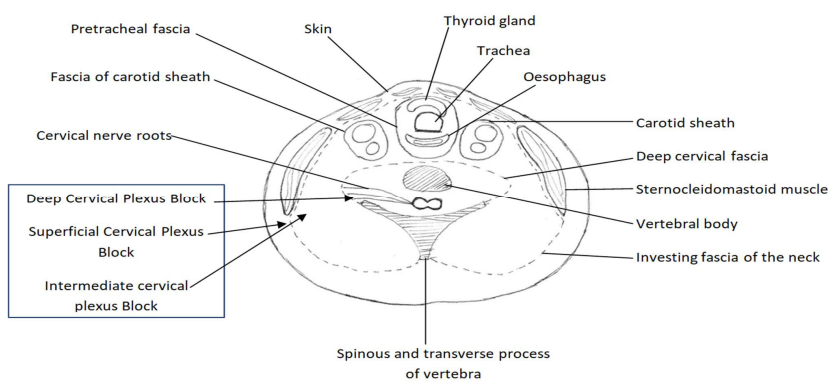

Figure 1: Schematic diagram of cross section of neck at $\mathrm{C} 4$ level showing the site of injection of the cervical plexus block: deep, superficial subcutaneous and intermediate (modified from Ramachandran et al..). ${ }^{[10]}$

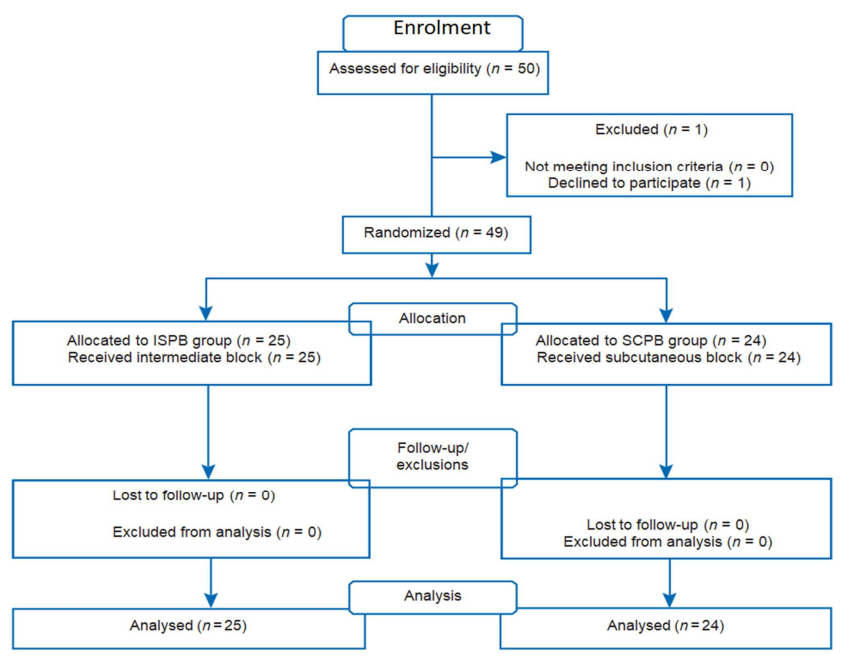

Figure 2: CONSORT flow diagram

Table 1: Patient characteristic and intraoperative data

Characteristics $\mid$ ICPB group $\mid$ SCPB group $\mid$ P*

\begin{tabular}{|l|l|l|l|}
\hline Characteristics & $\begin{array}{l}\text { ICPB group } \\
(\mathbf{n = 2 5 )}\end{array}$ & $\begin{array}{l}\text { SCPB group } \\
(\mathbf{n = 2 4 )}\end{array}$ & $\mathbf{P} *$ \\
\hline $\begin{array}{l}\text { Age (years) as } \\
\text { mean } \pm \text { SD }\end{array}$ & $52.1 \pm 11.6$ & $56.3 \pm 12.8$ & 0.23 \\
\hline $\begin{array}{l}\text { Gender } \\
\text { female/male) }\end{array}$ & $9 / 16$ & $8 / 17$ & 0.68 \\
\hline $\begin{array}{l}\text { Weight (kg) as } \\
\text { mean } \pm \text { SD }\end{array}$ & $63.9 \pm 15.2$ & $67.6 \pm 12.5$ & 0.35 \\
\hline ASA grade (I/II) & $9 / 16$ & $10 / 14$ & 0.68 \\
\hline $\begin{array}{l}\text { Surgical levels } \\
\text { One/Two level }\end{array}$ & $10 / 15$ & $9 / 15$ & 0.85 \\
\hline $\begin{array}{l}\text { Total fentanyl } \\
\text { consumption } \\
\text { (ugm) as } \\
\text { mean } \pm \text { SD }\end{array}$ & $245 \pm 25$ & $295 \pm 75$ & 0.002 \\
\hline $\begin{array}{l}\text { Duration of } \\
\text { surgery (min) as } \\
\text { mean } \pm \text { SD }\end{array}$ & $248 \pm 15$ & $236 \pm 19$ & 0.07 \\
\hline
\end{tabular}

*Calculated using Chi-square test or Student's t-test as appropriate, ICPB: Intermediate cervical plexus block, SCPB: Superficial cervical plexus block, ASA: American Society of Anaesthesiologists, SD: Standard deviation

Table 2: Quality of recovery score (QoR-40) at $24 \mathrm{~h}$ after surgery

\begin{tabular}{|l|l|l|l|}
\hline Parameters & $\begin{array}{l}\text { ICPB group } \\
(\mathbf{n = 2 5 )}\end{array}$ & $\begin{array}{l}\text { SCPB group } \\
(\mathbf{n = 2 4 )}\end{array}$ & $\mathbf{P}$ \\
\hline Emotional state & $41.7 \pm 3.1$ & $39.6 \pm 2.9$ & 0.018 \\
\hline $\begin{array}{l}\text { Physical } \\
\text { comfort }\end{array}$ & $55.2 \pm 3.3$ & $50.4 \pm 6.3$ & 0.001 \\
\hline $\begin{array}{l}\text { Psychological } \\
\text { support }\end{array}$ & $33.3 \pm 1.8$ & $31.2 \pm 2.2$ & 0.001 \\
\hline $\begin{array}{l}\text { Physical } \\
\text { independence }\end{array}$ & $22.7 \pm 2.1$ & $20.5 \pm 3.6$ & 0.011 \\
\hline Pain & $32.9 \pm 1.8$ & $31.4 \pm 2.9$ & 0.033 \\
\hline Total score & $186 \pm 9$ & $173 \pm 12$ & 0.001 \\
\hline
\end{tabular}

Data are shown as mean \pm SD, ICPB: Intermediate cervical plexus block, SCPB: Superficial cervical plexus block SD: Standard deviation

Table 3: NRS for postoperative pain up to $24 \mathrm{~h}$ after surgery

\begin{tabular}{|l|l|l|l|}
\hline $\begin{array}{l}\text { NRS at } \\
\text { various time } \\
\text { intervals }\end{array}$ & $\begin{array}{l}\text { ICPB group } \\
(\mathbf{n}=\mathbf{2 5})\end{array}$ & $\begin{array}{l}\text { SCPB group } \\
(\mathbf{n = 2 4})\end{array}$ & $\mathbf{P}$ \\
\hline $0 \mathrm{~h}$ & $2.24 \pm 0.663$ & $3.38 \pm 0.576$ & 0.001 \\
\hline $2 \mathrm{~h}$ & $2.44 \pm 0.583$ & $4.04 \pm 0.624$ & 0.001 \\
\hline $4 \mathrm{~h}$ & $3.12 \pm 0.526$ & $4.16 \pm 0.565$ & 0.002 \\
\hline $8 \mathrm{~h}$ & $3.40 \pm 0.577$ & $4.54 \pm 0.658$ & 0.002 \\
\hline $12 \mathrm{~h}$ & $3.24 \pm 0.523$ & $4.96 \pm 0.624$ & 0.001 \\
\hline $24 \mathrm{~h}$ & $4.08 \pm 0.400$ & $5.58 \pm 0.584$ & 0.001 \\
\hline
\end{tabular}

Data are shown as mean \pm SD, NRS: Numeric rating scale, ICPB: Intermediate cervical plexus block, SCPB: Superficial cervical plexus block SD: Standard deviation 
Table 4: Postoperative data

\begin{tabular}{|l|l|l|l|}
\hline Variables & $\begin{array}{l}\text { ICPB group } \\
(\mathbf{n = 2 5})\end{array}$ & $\begin{array}{l}\text { SCPB group } \\
(\mathbf{n = 2 4})\end{array}$ & P* \\
\hline $\begin{array}{l}\text { Cumulative morphine } \\
\text { consumption at 24 h } \\
\text { after surgery in mg, } \\
\text { as mean } \pm \text { SD }\end{array}$ & $7.5 \pm 2.4$ & $15.9 \pm 3.7$ & 0.001 \\
\hline Nausea, $\mathrm{n}$ & 1 & 6 & 0.035 \\
\hline Vomiting, $\mathrm{n}$ & 1 & 6 & 0.035 \\
\hline Dysphagia & 2 & 9 & 0.013 \\
\hline SpO2 <90\% & Nil & Nil & \\
\hline $\begin{array}{l}\text { Sedation score of } \\
<2 \text { or }>4\end{array}$ & Nil & Nil & \\
\hline
\end{tabular}

\section{Discussion}

Cervical plexus block has been used successfully as a sole anaesthetic technique or more commonly along with general anaesthesia for carotid endarterectomy, thyroid surgery and neck dissection. ${ }^{[9,10,19]}$ Despite its popularity and universal acceptability, it has been sparsely used in ACDF surgery where the cervical vertebrae are approached through the anterior neck. ${ }^{[20,21]}$

Cervical plexus and its branches can be blocked using three different techniques. In SCPB, the drug is deposited subcutaneously, above the investing fascia whereas in deep block, the drug is injected near the nerve routes. The third technique, ICPB, the local anaesthetic drug is injected between the investing fascia and deep cervical fascia, thereby providing more profound analgesia or anaesthesia of deeper structure of the neck region. ${ }^{[2]}$ The deep cervical plexus block is technically difficult to perform and has more incidence of complication than superficial blocks. ${ }^{[23]}$

Despite having a clear cut advantage of ICPB over SCPB, in a study conducted by Ramchandran et al. failed to demonstrate the better analgesia or anaesthesia profile of ICPB compared to SCPB. ${ }^{[10]}$ In their study they used landmark based technique which was essentially 'blind' and it was possible that some subcutaneous injection used for SCPB were actually made deeper than intended (and therefore actually sited intermediate) or vice versa (i.e. some intended intermediate injection were in fact subcutaneous). In our study all the blocks were performed under USG guidance, so the drug was deposited more reliably within the intended anatomical plane or space, resulting in better QoR40 score and reduced opioids consumption during the intraand postoperative period in ISPB group compared to SCBP group.

We used bilateral block in our study because the surgical incision in ACDF, reaches midline and a unilateral block unlikely to provide adequate analgesia. Mariappan et al. despite giving unilateral SCPB for ACDF surgery, the QoR40 at $24 \mathrm{~h}$ was 179 , which is similar to QoR-40 for SCPB group in our study. ${ }^{[20]}$ Again this can be explained by the fact that some of the subcutaneous injection may have accidentally become ISPB producing better QoR-40 score, as the author used landmark based blind technique.

The QoR-40 scoring system was developed by Myles et al. which is a valid, reliable and responsive tool for assessment of the quality of recovery after surgery and anaesthesia. ${ }^{[16]}$ It was further validated by Gornall et al. in their systemic review and meta-analysis. ${ }^{[15]}$ This scoring system has been used successfully for many surgical facilities, including neurosurgery. ${ }^{[16]}$

The investing layer of cervical fascia of the neck is a controversial topic and previous studies have questioned about the very existence of this layer. ${ }^{[12,24]}$ We agree with Pandit and colleagues who showed that injections given below the investing fascia of the neck diffuse into deep space, whereas injections placed subcutaneously did not. ${ }^{[1]}$ There was a 13 point improvement in QoR-40 in the ICPB when compared to SCPB group and the opioid consumption during the intra- and postoperative period was significantly less in ICPB group. The decrease in overall opioid consumption was probably responsible for the decrease incidence of PONV in ICPB group. The incidence of dysphagia was also less in ICPB group as the drug was deposited deep inside investing fascia, producing better pain relief.

There was some concern regarding safety profile of bilateral ICPB but previous studies have compared bilateral blocks to unilateral blocks and they did not notice any significant increase in the incidence of serious complications. ${ }^{[25,26]}$

To the best of our knowledge, for the first time, ultrasound guided, bilateral ICPB was compared with bilateral SCPB in patients undergoing ACDF surgery and the superior analgesia profile of ISPB was demonstrated.

There were certain limitations to our study. This was a single centre study and numbers of participants were limited. We did not measure the time taken to complete the block procedure. Our study was adequately powered to show a difference of ten points in the quality of recovery, but it was not adequately powered to show any differences in postoperative opioid consumption and side effects. We followed the patients for only the first $24 \mathrm{~h}$; hence, some of the complications of block and readmission would have been missed.

\section{Conclusion}

Pre-incisional, ultrasound guided ISPB, compared to SCPB significantly improves the quality of recovery after single-or two level ACDF, making it a simple and effective technique for improving the quality of recovery in patients undergoing anterior neck surgeries. We also strongly believe the existence of the investing layer of cervical fascia of the neck and our study has indirectly proved it.

\section{References}

1. Yuen J, Whitfield P. Anterior cervical discectomy and fusion (ACDF) for degenerative cervical disease - Six decades on. ACNR 2017; 17(1); $5-10$.

2. Frempong-Boadu A, Houten JK, Osborn B, et al. Swallowing and speech dysfunction in patients undergoing anterior cervical discectomy and fusion: a prospective, objective preoperative and postoperative assessment. J Spinal Disord Tech 2002; 15: 362-8.

3. Bazaz R, Lee MJ, Yoo JU. Incidence of dysphagia after anterior cervical spine surgery: a prospective study. Spine (Phila Pa 1976) 2002; 27: 2453-8.

4. Niijima K, Malis L. Preventive superficial cervical plexus block for postoperative cervicocephalic pain in neurosurgery. Neurol Med Chir (Tokyo) 1993;33:365-7 
5. Suk KS, Kim KT, Lee SH, Park SW. Prevertebral soft tissue swelling after anterior cervical discectomy and fusion with plate fixation. Int Orthop 2006; 30: 290-4

6. Fountas KN, Kapsalaki EZ, Nikolakakos LG, et al. Anterior cervical discectomy and fusion associated complications. Spine 2007; 32: 2310-

7. Sagi HC, Beutler W, Carroll E, Connolly PJ. Airway complications associated with surgery on the anterior cervical spine. Spine (Phila Pa 1976) 2002; 27: 949-53.

8. Elvir-Lazo OL, White PF. The role of multimodal analgesia in pain management after ambulatory surgery. Curr Opin Anaesthesiol 2010; 23: 697-703

9. AndrieuG, Amrouni H, Robin E, Carnaille B, Wattier JM, Pattou F. Analgesic efficacy of bilateral superficial cervical plexus block administered before thyroid surgery under general anaesthesia. $\mathrm{Br} \mathrm{J}$ Anaesth 2007;99:561-6

10. Ramachandran SK, Picton P, Shanks A, Dorje P, Pandit JJ. Comparison of intermediate vs subcutaneous cervical plexus block for carotid endarterectomy. Br J Anaesth 2011;107:157-63

11. Pandit JJ, Dutta D, Morris JF. Spread of injectate with superficial cervical plexus block in humans: an anatomical study. Br J Anaesth 2003;91:733-5

12. Nash L, Nicholson HD, Zhang M. Does the investing layer of the deep cervical fascia exist? Anesthesiology 2005;103:962-8

13. Telford RJ, Stoneham MD, Correct nomenclature of superficial cervical plexus blocks. Br J Anaesth 2004;775

14. Casutt M, Job K, Beutler J, Duwe J, Veit P. Intermediate cervical plexus block for carotid endarterectomy: A case series of the spread injectate. J Anesth Clinic Res 2011;2:123

15. Gornall BF, Myles PS, Smith CL, et al. Measurement of quality of recovery using the QoR-40: a quantitative systematic review. $\mathrm{Br} J$ Anaesth 2013; 111: 161-9

16. Myles PS, Hunt JO, Nightingale CE, et al. Development and psychometric testing of a quality of recovery score after general anesthesia and surgery in adults. Anesth Analg 1999; 88: 83-90

17. Koinig H, Wallner T, Marhofer P, Andel H, Horauf K, Mayer N Magnesium sulfate reduces intra- and postoperative analgesic requirements. Anesth Analg 1998;87:2016-10

18. Leslie K, Troedel S, Irwin K, et al. Quality of recovery from anesthesia in neurosurgical patients. Anesthesiology 2003; 99: 1158-65.

19. Salwa Mohamed SH, Hanaa Mahmoud EB, Eiad Ahmed R, Ahmed Musaad EF, Ehsan Mohamed Abd ER. Efficacy of unilateral combined (superficial and deep) cervical plexus block as a preemptive analgesia for unilateral neck dissection surgery. Egyptian Journal of Anaesthesia 2012; 28:275-279.

20. Mariappan R, Mehta J, Nagappa M, Manninen P, Venkatraghavan L. Effect of superficial cervical plexus block on postoperative quality of recovery after cervical discectomy and fusion: a randomized controlled trial. Can J Anesth 2015;62:883-890.

21. Wang H, Ma L, Yang D, Wang T, Wang Q, Zhang L, Ding W. Cervical plexus anaesthesia versus general anesthesia for anterior cervical discectomy and fusion surgery, a randomized clinical trial. Medicine (Baltimore) 2017;96:7

22. Stoneham MD, Stamou D, Mason J. Regional anaesthesia for carotid endarterectomy. Br J Anaesth 2014;114:372-83

23. Pandit JJ, Satya-Krishna R, Gration P. Superficial or deep cervical plexus block for carotid endarterectomy: a systemic review of complications. Br J Anaesth 2007;99:159-69

24. Pandit JJ, Dorje P, Satya-Krishna R. Investing layer of the cervical fascia of the neck may not exist. Anesthesiology 2006;104:1344

25. Kulkarni LS, Braverman LE, Patwardhan NA. Bilateral cervical plexus block for throidectomy and parathyroidectomy in healthy and high risk patients. J Endcrinol Invest 1996;19:714-8

26. Su Y, Zhang Z, Zhang Q, Zhang Y, Liu Z. Analgesic efficacy of bilateral superficial and deep cervical plexus block in patients with secondary hyperparathyroiodism due to chronic renal failure. Ann Surg Treat 2015;89:325-9

Copyright: (ㅇ the author(s), publisher. Academia Anesthesiologica International is an Official Publication of "Society for Health Care \& Research Development". It is an open-access article distributed under the terms of the Creative Commons Attribution Non-Commercial License, which permits unrestricted non-commercial use, distribution, and reproduction in any medium, provided the original work is properly cited.

How to cite this article: Sahoo SK, Souvagya P, Chandra PS. Comparison of Intermediate VS Subcutaneous Superficial Cervical Plexus Block for Anterior Cervical Discectomy and Fusion: A Prospective Randomized Controlled Study. Acad. Anesthesiol. Int. 2019;4(2):209-213.

DOI: dx.doi.org/10.21276/aan.2019.4.2.48

Source of Support: Nil, Conflict of Interest: None declared. 